Brit. J. industr. Med., 1952, 9, 296.

\title{
THE ROLE OF STAPHYLOCOCCAL INFECTION IN BEAT DISORDERS OF MINERS
}

\author{
BY \\ J. B. ATKINS and J. MARKS \\ From the Medical Inspectorate of Mines, and the Public Health Laboratory, Cardiff
}

(RECEIVED FOR PUBLICATION APRIL 1, 1952)

Since the report of Collis and Llewellyn (1924) the incidence of beat knee and elbow per 1,000 underground workers has increased more than tenfold. It is evident that the ineffectiveness of preventive measures which they noted has not been overcome. In 1949, 9,900 cases of beat knee and 1,500 of beat elbow were certified. Some of the increase since 1922 may be due to slight changes in defining the disorders and greater readiness to seek attention. However, a substantial part appears real and attributable to both the more frequent working of narrow seams and the increased use of mining methods which involve more kneeling. Despite their importance as the second most common of all the prescribed industrial diseases, little work on these disorders has been published. The problem has recently been discussed by Watkins (1951), who emphasized the importance of early treatment in view of the failure of current preventive measures.

In contrast to the more general survey of Collis and Llewellyn the present work attempts to identify the factors responsible for beat conditions by a detailed study, lasting a year, of men employed in a single low seam where a high incidence of the disorders was expected. Much of the investigation was bacteriological, for previously the traumatic element in pathogenesis had received more attention, to the especial neglect of the study of individual predisposition. The importance of this predisposition will be shown below and evidence submitted that it depends upon susceptibility to staphylococcal infection, particularly of hair follicles.

\section{Working Environment}

A newly opened seam of thin section, which was to be manned by workers unaccustomed to such conditions, was selected for this study.

The few men who had ever worked in low seams had not done so in the previous 12 months. There were approximately 215 men employed for more than a month at the coal face of whom $75 \%$ volunteered for observation. Most of the men were observed from the time production began. The district chosen had two double-unit conveyor faces in a seam varying from $2 \mathrm{ft}$. to $4 \mathrm{ft}$. in thickness except for occasional stretches with more height. Continual kneeling at work was necessary throughout the period of observation, except that in one section standing was possible during the third quarter of the survey.

In all faces the seam was constantly intersected by a band of " brass" (iron pyrites) but the coal itself was comparatively clean. Ash content averaged $26 \%$, and volatile $21 \%$. Although microscopically no excess of fusein was evident, mineral particles other than coal were conspicuous. The coal fragmented on handling into very hard pieces with noticeably sharp angles. This textural quality of the coal, together with the admixture of " brass", meant that the men had to kneel on highly abrasive material. The floor itself was of moderately hard fireclay with soft patches, and had an irregular surface. In the first half of the survey water was constantly on the floor in one of the four faces.

Ventilation rates were $2,300-4,000 \mathrm{cu}$. ft. $/ \mathrm{min}$. during the first eight months. Corresponding values for air velocities and temperatures are not available, but working conditions appeared comfortable. In the latter four months an air bridge permitted ventilation rates of 6,000 to $12,000 \mathrm{cu} . \mathrm{ft} . / \mathrm{min}$., and temperatures were $68^{\circ} \mathrm{F}$. dry bulb and $64-65^{\circ} \mathrm{F}$. wet bulb (relative humidity $80-85 \%$ ).

It was difficult to observe the men since they could be seen only outside working hours. There was no pithead bath at which the men could be seen with clean skins, but fortunately they cooperated well.

Special arrangements were made for the initial interview, many men being seen in their homes after bathing to permit of an assessment of their skin 
condition. At this interview histories were taken of previous staphylococcal infection, beat disorders, and of previous working conditions. The men were assigned, according to their type of skin, to one of the four groups described below. Swabs were taken from nose, throat, and skin, and any abnormality of knees or elbows was noted. Skin swabs were taken from the front of the knees.

During the subsequent 12 months each man was examined as far as possible at monthly intervals, and questioned about the condition of his knees or elbows, the use of special protective measures, such as knee pads or spirit applications, and alterations in working conditions. Swabs were taken from carrier sites (nose, throat, and skin). Any beat lesion, cut or septic skin lesion found on examination was swabbed, some beat lesions also being needled for culture. Special visits were made to men with " beats" who were absent from work and repeated when disability was prolonged. The survey began in June, 1950. In the following October and November, by which time almost all the workers had been recruited for the new district, the' serum levels of staphylococcal $\alpha$-antitoxin of the majority of the men were estimated. The attendance and accident records of face-workers were noted and the seam was visited in most months to note its height, condition of the floor, temperatures, ventilation, and other working conditions.

Although the survey was intended only for observation of the men at risk and intervention was avoided if possible, medical advice, especially for a developing lesion, could hardly have been refused if the confidence and cooperation of the men were to be retained. As the survey proceeded, men reported trouble earlier, and simple treatment, sometimes with temporary transfer to work off the knees, undoubtedly aborted or ameliorated many cases of beat disorder. More suitable employment was found for one of the men who was especially prone to beat disorders.

\section{Bacteriological Methods}

All swabs were inoculated directly on to $2.5 \%$ sheep blood agar. After 24 hours' incubation at $37^{\circ} \mathrm{C}$. in air with $20 \% \mathrm{CO}_{2}$ haemolytic colonies of staphylococci were picked and examined for the production of coagulase and $\alpha$-toxin. Only strains producing both factors were considered pathogenic. The techniques used and the criteria of pathogenicity adopted have been described and discussed fully elsewhere (Marks, 1952). Several beat lesions were not swabbed either because there was antiseptic ointment on the skin or because the patients could not be seen until the lesions had subsided. Nasal swabs were taken from one nares only. Skin swabs were moistened and rubbed over approximately $10 \mathrm{sq} . \mathrm{cm}$. of the skin of one knee; the unaffected one was also tested when a beat knee was present. Carriage over the knee was thought to be more relevant to the investigation than at the other sites usually tested. On most occasions swabs had to be stored overnight at room temperature before culture. Streptococcus pyogenes was sometimes isolated from infected cuts but not from any beat condition in this survey.

The serum levels of staphylococcal $\alpha$-antitoxin were estimated in 117 men. Titrations were conducted at the $\mathrm{Lh} / 10$ level with intervals of $20 \%$, using rabbit red cells.

All strains of pathogenic staphylococci isolated during the survey were stored until its end.

\section{Survey Findings}

Clinical Types of Beat Disorder.-The Industrial Injuries Act recognizes two types of beat disorder, subcutaneous cellulitis and acute bursitis. The aetiology of beat hand, which is always a cellulitis, differs from that of beat knee and elbow and was not studied; only one case was encountered. Fifty-seven attacks of beat-knee and three of beatelbow were observed during the survey : it does not appear necessary, however, to distinguish between these disorders. Of the 60 attacks, only 31 , involving 25 men, were admitted for benefit under the Industrial Injuries Act. Twenty-four of the attacks for which benefit was awarded were considered to have arisen as a complication of follicular infection, one was acute bursitis and in six the aetiology was doubtful. The case of acute bursitis was the immediate consequence of a blow from falling stone. Every one of the 29 attacks of beat disorder for which benefit was not claimed was manifestly the sequel to an infected follicle. Many septic cuts and abrasions were observed but none initiated a beat condition. In no attack of the "folliculitis" type was there a history of special precipitating trauma. Case 13 is representative of the "folliculitis" group.

Case 13.-A fireman, aged 32, with a greasy skin and a history of recurrent boils, developed a beat knee. A heavy growth of pathogenic staphylococci was obtained from the lesion, which began as folliculitis over the left tibial spine, rapidly developing into cellulitis. After three weeks' absence, he worked for two months in a district where no kneeling was necessary. Soon after his return to the low seam he developed boils of the neck ; swabs from nose, knees, and neck now gave heavy growths of pathogenic staphylococci. Two weeks later cellulitis developed round one of several infected follicles on the right knee. Nasal and lesion swabs were again positive. He lost another 12 days' work and then obtained a permanent transfer to another district where kneeling was not required. He was observed for six months more but he had no further trouble with his knees, although remaining a heavy nasal carrier. 
The relationship between attacks presenting as acute bursitis and those with staphylococcal cellulitis is of some interest. Immediate extension to an underlying bursa was only seen in three attacks of cellulitis, but several men developed a bursal effusion a few weeks after the subsidence of a folliculitis or a cellulitic beat attack. When first seen, the six attacks of doubtful aetiology would have been diagnosed by most observers as acute bursitis. However, as the history of one of these attacks shows, continued observation in such instances may prove an infective origin.

Case 3.-A conveyor-turner, aged 40 , with a very dry and hairy skin was observed to be a nasal and skin carrier for four months before he developed a tense, tender swelling over the left tibial spine. There was no preceding trauma or visible local skin infection but he had some mildly-infected hyperkeratotic follicles about the face. The condition was then considered to be an acute bursitis. However, when the swelling subsided, a small tender area of skin was detected, which appeared to be an infected follicle buried in hyperkeratinized skin. He returned to work after 14 days' absence, but five months later an obvious follicular infection of the same knee developed into a severe beat condition which yielded staphylococci of the same phage-type as had been consistently carried in the nose for 10 months. It is suspected from the course of this man's first attack and the subsequent history that the original diagnosis of acute bursitis was mistaken.

It seems probable that the role of follicular infection in beat disorder is often overlooked, trauma alone or other types of infection being mistakenly held responsible for acutely swollen and painful bursae. It is noteworthy that all the men suffering attacks of doubtful aetiology were heavy carriers of pathogenic staphylococci ; in addition, one had a history of recent staphylococcal infection and another a greasy skin. As will be shown below, these are factors especially associated with folliculitis and the cellulitic type of beat attack.

Morbidity.-In analysing our results, we have seldom distinguished between beat cases admitted to benefit after three days absence from work and those needing little or no time off. Although benefit cases are usually the more severe, there is no other clinical difference between the two groups and whether men lose time or not often depends on other factors.

The occupational groups most affected by beat conditions, with their complements of men, were colliers (124), cuttermen (12), prop-drawers (10), conveyor-turners (6), and officials (13). During the survey period 41 men in these groups suffered from beat disorders, 597 days being lost by benefit cases alone ( 28 attacks in 22 men). In the same time they lost 1,821 days through injury. Other occupational groups contributed only five beat cases, including three benefit patients who lost 47 days' work. Loss of output due to absences of less than four days and the lowered efficiency of the many men who continued to work despite beat disorder was no doubt considerable. In addition, experience of the disorder is one of the factors prompting men to leave the mining industry.

Effect of Hardening.-It is widely believed that after a period of the work on the knees susceptibility to beat disorder diminishes. Variation in many factors during the year's study prevents a clear-cut answer to this question. A high incidence of beat disorder was certainly observed during the first two months that the men worked in the low seam. This appeared to be due to especially susceptible men rapidly falling victims; if the 13 men suffering more than one attack during the survey are excluded, the incidence of beat disorder varied little with length of exposure.

In 25 men absent a month or more for reasons other than beat disorder, there was a lower incidence than average in the three months following their return to work. No case of beat disorder occurred in the six weeks following a two weeks' strike after the end of the survey. It appears, therefore, that the apparent lowering of risk with time is due to the elimination of men especially susceptible to staphylococcal infection, by transfer, invaliding, or the acquisition of immunity in the bacteriological sense. Periods of rest from kneeling, rather than increasing risk, appeared to be beneficial.

Occupation.-The highest incidence $(25 \%)$ of benefit cases occurred amongst the 28 cuttermen, prop-drawers, and conveyor-turners. The numbers are small but it does appear that men in these occupations incur a special risk from having to move about the coalface on their knees; other factors predisposing to beat disorder were not especially frequent amongst them. Their length of working-week (mean 5.1 shifts) was very little greater than that of the 40 packers ( 4.8 shifts) who contributed only one benefit case, but were much less obliged to kneel at their work. There was a moderate incidence in the 124 colliers, 18 benefit cases occurring among them.

Knee-pads. - Collis and Llewellyn (1924) advised the use of knee-pads as an important defence against beat knee. Few of the miners we observed wore pads, although patches of canvas were often used to protect trousers against wear. Sixteen men 
wore strapped knee-pads at one time or other but most abandoned them after a few weeks; only one wore pads throughout the year. Pads did not protect one youth from an attack of beat knee after only eight days' work, nor another who had adopted them after two attacks.

\section{Results of Bacteriological Investigation}

In the sections which follow all beat cases are considered together without regard to severity or benefit claims. The analyses deal only with men seen on four or more occasions at intervals of at least a month, but where length of observation was irrelevant a few more subjects were included. Few men were observed for less than six months, many for 12 months. Since approximately $25 \%$ of the men working in the district studied did not volunteer, an accurate comparison of beat cases and unaffected men is not possible. Most comparisons have therefore been made between beat cases and a set of matched controls, each closely corresponding to a beat case in age, occupation, number of shifts worked, and period under observation. It is known that no man who evaded observation lost time owing to beat disorder, and it is unlikely that many minor affections went unreported.

Carriage of Pathogenic Staphylococci Related to Morbidity.-In the following account the terms "carriage" and "positive swabs" imply the isolation of pathogenic staphylococci. Two thousand two hundred swabs were examined. The results for swabs taken from carrier sites and the skin over beat lesions (designated " beat lesion swabs") are given in Table 1. Only initial beat lesion swabs from the first attack experienced are recorded and other types of lesion, such as boils or infected cuts, are not considered here. Carriage of pathogenic staphylococci was more than twice as frequent, at each site tested, amongst men developing beat disorder as amongst matched controls. The higher incidence in affected men was not secondary to their beat lesions, carriage being as frequent before lesions developed as after; nor was it due to disproportionate swabbing of heavy carriers. Pathogenic staphylococci were isolated from $59 \%$ of the initial beat lesion swabs, an isolation rate three times that for skin swabs from the same group of men and 11 times that for skin swabs from matched controls. More positive beat lesions swabs might have been obtained if certain of the men could have been seen before their lesions had subsided. In $30(27 \%)$ of the 112 men swabbed at four or more sessions (mean, 6.0 sessions), carriage of pathogenic staphylococci was not found on any
TABLE 1

INCIDENCE OF PATHOGENIC STAPHYLOCOCCI IN RELATION TO BEAT DISORDERS

\begin{tabular}{|c|c|c|c|c|c|c|c|c|c|}
\hline \multirow[b]{2}{*}{ Source } & \multicolumn{3}{|c|}{$\begin{array}{l}\text { Beat } \\
\text { Cases }\end{array}$} & \multicolumn{3}{|c|}{$\begin{array}{l}\text { Matched } \\
\text { Controls }\end{array}$} & \multicolumn{3}{|c|}{$\begin{array}{l}\text { All Unaffected } \\
\text { Men } \dagger\end{array}$} \\
\hline & $\begin{array}{l}\text { Swabs } \\
\text { Exam- } \\
\text { ined }\end{array}$ & $\begin{array}{l}\text { No. } \\
\text { Posi- } \\
\text { tive }\end{array}$ & $\begin{array}{l}\% \\
\text { Posi- } \\
\text { tive }\end{array}$ & $\begin{array}{l}\text { Swabs } \\
\text { Exam- } \\
\text { ined }\end{array}$ & $\begin{array}{l}\text { No. } \\
\text { Posi- } \\
\text { tive }\end{array}$ & $\begin{array}{l}\% \\
\text { Posi- } \\
\text { tive }\end{array}$ & $\begin{array}{l}\text { Swabs } \\
\text { Exam- } \\
\text { ined }\end{array}$ & $\begin{array}{l}\text { No. } \\
\text { Posi- } \\
\text { tive }\end{array}$ & $\begin{array}{l}\% \% \\
\text { Posi- } \\
\text { tive }\end{array}$ \\
\hline Nose... & 241 & 110 & 46 & 235 & 46 & 20 & 487 & 123 & 25 \\
\hline Throat & 217 & 14 & 6 & 194 & 2 & 1 & 440 & 12 & 3 \\
\hline Skin .. & 241 & 42 & 17 & 229 & 11 & 5 & 487 & 38 & 8 \\
\hline $\begin{array}{l}\text { Beat** } \\
\text { lesion }\end{array}$ & 37 & 22 & 59 & - & - & - & - & - & - \\
\hline
\end{tabular}

* Nine unswabbed beat lesions do not appear in the table. $\dagger$ Includes matched controls.

occasion. Of these 30 men, only six developed a beat condition compared with 36 of the 82 men showing carriage at one time or another.

The association of nasal carriage with beat disorder contrasts with its apparent lack of significance in staphylococcal infections of wounds (Williams and Miles, 1949) although skin carriage is associated with both conditions.

To determine whether men prone to beat conditions can be identified by their carriage rate, the results of the first two swabbings have been analysed (Table 2). Men found to be carriers on both occasions will be termed " heavy carriers". There were 24 heavy carriers amongst 45 beat cases (53\%) but only five amongst the matched controls $(11 \%)$. The interval between swabbings was one month or more.

Skin Type, Morbidity, and Carriage of Pathogenic Staphylococci.-At their first interview the men were assigned, according to their skin types, to one of four broad groups. Greasy and abnormally hairy skins are two which require no special explanation. Men with fair, transparent skins were allotted to a type designated "fair". The remaining type was termed "seborrhoeic"

TABLE 2

CARRIAGE OF PATHOGENIC STAPHYLOCOCCI AND SUSCEPTIBILITY TO BEAT DISEASE

\begin{tabular}{c|c|c|c|c|c|c|c}
\hline $\begin{array}{c}\text { Type of } \\
\text { Subject }\end{array}$ & $\begin{array}{c}\text { No. } \\
\text { of } \\
\text { Men }\end{array}$ & $\begin{array}{c}\text { First } \\
\text { Swabbing }\end{array}$ & $\%$ & $\begin{array}{c}\text { Second } \\
\text { Swabbing }\end{array}$ & $\%$ & $\begin{array}{c}\text { Both First } \\
\text { and Second } \\
\text { Swabbings }\end{array}$ & $\%$ \\
\hline Beat cases & 45 & 28 & 62 & 31 & 69 & 24 & 53 \\
\hline $\begin{array}{c}\text { Matched } \\
\text { controls }\end{array}$ & 45 & 12 & 27 & 10 & 22 & 5 & 11 \\
\hline $\begin{array}{c}\text { All } \\
\text { unaffected } \\
\text { men }\end{array}$ & 85 & 27 & 32 & 29 & 34 & 15 & 18 \\
\hline
\end{tabular}

* Nose, throat, or skin, or any combination of these. 
but included many men with but a slight tendency to seborrhoea. "The incidence of beat disorder and heavy carriage in men of different skin types is shown in Table 3. Men with greasy skins were the most susceptible to beat conditions, 15 out of 26 being affected. There was little difference between the other groups, which altogether had 31 with beat conditions out of a total of 107 . Heavy carriage was found in approximately one third of the men with greasy, seborrhoeic or hairy skins, but in only one of the 20 men with "fair" skins.

TABLE 3

RELATION OF SKIN TYPE TO SUSCEPTIBILITY TO BEAT DISORDER AND CARRIAGE OF PATHOGENIC STAPHYLOCOCCI

\begin{tabular}{|c|c|c|c|c|c|}
\hline \multirow{2}{*}{$\begin{array}{l}\text { Group of } \\
\text { Men }\end{array}$} & \multirow{2}{*}{$\begin{array}{c}\text { No. of } \\
\text { Men }\end{array}$} & \multicolumn{4}{|c|}{ Type of Skin } \\
\hline & & Greasy & Fair & Hairy & $\begin{array}{l}\text { Sebor- } \\
\text { rhoeic }\end{array}$ \\
\hline Beat cases. . & 46 & 15 & 6 & 3 & 22 \\
\hline Matched controls. . & 46 & 6 & 7 & 4 & 29 \\
\hline All men $\ldots$ & 133 & 26 & 20 & 9 & 78 \\
\hline Heavy carriers & 39 & 10 & 1 & 3 & 25 \\
\hline
\end{tabular}

Serum Levels of Staphylococcal $\alpha$-Antitoxin.The serum $\alpha$-antitoxin levels of 117 men were estimated, mostly after one or two months' clinical observation. The relationship of the findings to other factors studied is complex but may be summarized as follows. Men with high $\alpha$-antitoxin levels ( 1.0 unit or more per ml.) had a very high incidence of beat disorders and staphylococcal infection in the period of the survey and the two years preceding it and carried pathogenic staphylococci more frequently than the remainder; most were aged 30 or less. It was concluded that high antitoxin levels were due to recent staphylococcal infections, indicating a previous lack of resistance. There was some evidence that men with high antitoxin levels following recent infection continued to be especially susceptible to staphylococcal infections.

Beat disorder in men with low and medium serum $\alpha$-antitoxin levels $(<1.0$ units per $\mathrm{ml}$.) was often associated with heavy carriage of pathogenic staphylococci. In contrast this association was not evident in men with high antitoxin levels. The significance of these observations is uncertain, but they may indicate that the effect of carriage in men with high antitoxin levels is overshadowed by other factors predisposing to infection.

Staphylococcal Phage-typing.-In 15 men (10 beat cases and five with boils or septic injuries) pathogenic staphylococci were first isolated from carrier sites and subsequently from lesions. In 11 of these 15 men (six beat and five other cases) the phagetype of the infecting strain and of that previously carried was identical (10 cases), or both were untypable (one case). In a further 19 men (eight beat and 11 other cases) carriage was absent or not sought before the lesion appeared but was present concurrently or subsequently. In 14 of these (seven beat and seven other cases) the infecting and carrier strains belonged to the same phage-type (nine cases), or were both untypable (five cases).

From these results it appears that beat disorder and staphylococcal skin infections are usually due to strains of staphylococci previously harboured. As noted by Williams and Miles (1949), a proportion of the discrepancies in phage-type may have resulted from sampling a flora containing more than one type. Some persistent carriers yielded staphylococci of the same phage-type throughout the 12-month survey period.

\section{Previous History and Susceptibility to Beat Disorders}

Men with histories of previous beat conditions or recent staphylococcal infection suffered a high incidence of beat disorder during the survey period. Recent infection was defined as that occurring in the two years preceding the survey; more remote staphylococcal infection was not of prognostic value. The only infections of note encountered were boils and severe widespread folliculitis. In Table 4 the proportion of beat cases with such histories is shown to be twice that observed in matched controls, or in unaffected men in general. During the survey period beat disorders affected 11 of 19 men who had recently suffered from staphylococcal infection and 13 of 24 who had contracted a beat condition at any time previously.

\section{Incidence of Beat Disorders at Different Ages}

The effect of age on the incidence of beat disorders was not great ; it is most clearly seen in a single occupational group. Thus, 13 of 39 colliers aged 20 or less developed a beat condition, compared with 12 of 52 colliers over 20 years of age. Factors predisposing to beat disorders were not distributed evenly amongst different age-groups. In the younger men many of the beat cases had greasy skins or a history of recent staphylococcal infection. These factors were less common in older beat cases, which, however, often had a history of a previous beat condition. The association of a heavy carriage of pathogenic staphylococci with beat conditions was prominent at all ages. 
TABLE 4

PREVIOUS HISTORY OF BEAT CASES AND UNAFFECTED MEN

\begin{tabular}{c|c|c|c|c|c}
\hline $\begin{array}{c}\text { Type of } \\
\text { Subject }\end{array}$ & $\begin{array}{c}\text { No. in } \\
\text { Each } \\
\text { Group }\end{array}$ & $\begin{array}{c}\text { Recent } \\
\text { Staphy- } \\
\text { lococcal } \\
\text { Infec- } \\
\text { tion }\end{array}$ & $\begin{array}{c}\text { Previous } \\
\text { Beat } \\
\text { Affec- } \\
\text { tion } \\
\text { of any } \\
\text { date) }\end{array}$ & $\begin{array}{c}\text { Men } \\
\text { with } \\
\text { History } \\
\text { of (1) } \\
\text { (2) or } \\
\text { Both }\end{array}$ & $\begin{array}{c}\text { Inci- } \\
\text { dence } \\
\text { of } \\
\text { Group } \\
(3)\end{array}$ \\
\hline Beat cases & 46 & 11 & 13 & 19 & 41 \\
\hline Matched controls. & 46 & 5 & 5 & 9 & 20 \\
\hline All unaffected men & 82 & 8 & 11 & 18 & 22 \\
\hline Totals & 128 & 19 & 24 & 37 & 29 \\
\hline
\end{tabular}

\section{Summarized Analysis of Predisposing Factors}

In Table 5 the incidence of chief predisposing factors is compared in beat cases and unaffected men. Thirty-nine beat cases, but only 19 of the matched controls, possessed one or more predisposing factors, a difference which is highly significant statistically $\left(\chi^{2}=16.8, P<0.01\right)$. The difference is also significant when men with two or more factors are considered; 17 such men were found amongst the beat cases but only two amongst the matched controls.

The effect of predisposing factors is most clearly seen in the men working in the high-risk occupations already defined, more of whom came under close observation. If men with a relatively short exposure to risk (less than 120 shifts during the survey) are excluded there remain 125 in these occupations, of whom 105 were studied. Amongst the latter, 32 of the 58 men with predisposing factors developed beat disorder compared with four of 47 men lacking them. At least one of the 26 men who escaped beat disorder despite predisposition was affected shortly after the end of the survey. Amongst

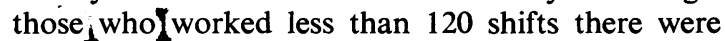

TABLE 5

INCIDENCE OF FACTORS PREDISPOSING TO BEAT DISORDERS

\begin{tabular}{|c|c|c|c|c|c|c|c|}
\hline \multirow[b]{2}{*}{$\begin{array}{c}\text { Type } \\
\text { of } \\
\text { Subject }\end{array}$} & \multirow[b]{2}{*}{$\begin{array}{c}\text { No. } \\
\text { in } \\
\text { Each } \\
\text { Group }\end{array}$} & \multicolumn{5}{|c|}{ Number of Subjects with } & \multirow{2}{*}{$\begin{array}{c}\text { No. } \\
\text { of } \\
\text { Men } \\
\text { with } \\
\text { Two } \\
\text { or } \\
\text { More } \\
\text { Factors }\end{array}$} \\
\hline & & $\begin{array}{c}\text { Greasy } \\
\text { Skins }\end{array}$ & $\begin{array}{c}\text { Recent } \\
\text { Staphy- } \\
\text { lococcal } \\
\text { Infec- } \\
\text { tion }\end{array}$ & $\begin{array}{l}\text { His- } \\
\text { tory of } \\
\text { Beat } \\
\text { Dis- } \\
\text { order }\end{array}$ & $\begin{array}{c}\text { Heavy } \\
\text { Staphy- } \\
\text { lococcal } \\
\text { Car- } \\
\text { riage }\end{array}$ & $\begin{array}{c}\text { Any } \\
\text { of } \\
\text { Factors } \\
\text { (1) to } \\
\text { (4) }\end{array}$ & \\
\hline $\begin{array}{l}\text { Beat } \\
\text { cases }\end{array}$ & 46 & 15 & 11 & 13 & 24 & 39 & 17 \\
\hline $\begin{array}{l}\text { All un- } \\
\text { affected } \\
\text { men* }\end{array}$ & $\begin{array}{c}82 \\
(46)\end{array}$ & $\begin{array}{l}11 \\
(6)\end{array}$ & $\begin{array}{c}8 \\
(5)\end{array}$ & $\begin{array}{l}11 \\
(5)\end{array}$ & $\begin{array}{l}15 \\
(5)\end{array}$ & $\begin{array}{c}34 \\
(19)\end{array}$ & $\begin{array}{c}9 \\
(2)\end{array}$ \\
\hline All men & 128 & 26 & 19 & 24 & 38 & 73 & 26 \\
\hline
\end{tabular}

* These include the matched controls, figures for which are given in brackets. five beat cases, four of which had predisposing factors, multiple in two cases.

The mean number of shifts worked in the district by beat cases before lesions appeared is of some interest when correlated with predisposing factors.

(1) Greasy skins

(2) Recent staphylococcal infection

(3) Heavy carriage as sole predis-

posing factor
o predisposing factor..

$$
\begin{array}{r}
61 \text { shifts }(\mathrm{N}=13 \text { S.E. }=16) \\
66 \text { shifts }(\mathrm{N}=17 \text { S.E. }=10) \\
111 \text { shifts }(\mathrm{N}=10 \text { S.E. }=21)
\end{array}
$$

Groups (1) and (2) are not mutually exclusive. Work records were not available for five men.

\section{Discussion}

Since most attacks of beat knee or elbow are demonstrably staphylococcal infections, it is apparent that factors other than trauma are also concerned in their pathogenesis. These factors and the problems they present are common to both beat disorders and staphylococcal skin infections. Most staphylococcal infections of a single follicle quickly heal if the follicle and the surrounding skin are protected against friction and immobilized. In contrast, an infected follicle exposed to pressure, friction, and movement heals slowly or may give rise to cellulitis or a boil, probably owing to the severance of the tissue barrier which normally can confine such an infection. It is widely believed that cuts and abrasions afford entrance to the organisms causing beat cellulitis, but although many such injuries were observed during the survey, none developed into a beat disorder.

In acute bursitis there is usually either a history of a severe injury to the bursa or an extension to it of infection from an adjacent cellulitis. The causes of chronic bursitis are less obvious. Collis and Llewellyn (1924) considered chronic bursitis to be unrelated to beat disorders. Since we have observed that effusions sometimes develop in knees recently the seat of follicular infections, further investigation of the aetiology of chronic bursitis seems necessary.

Preventive measures against beat disorders may be directed at either the infective or traumatic factors in their aetiology. In British coalmines the use of knee-pads to reduce trauma, although widespread, is failing to stop the steady increase in the incidence of beat knee. It is probable that pads increase liability to follicular infection because of skin maceration beneath them. Coal particles inevitably accumulate under the pads and reduce protection against trauma. Unless these deficiencies of knee-pads can be overcome, no substantial benefit from extending their use is to be anticipated.

In planning operations in a low seam the influence of duration of exposure to trauma, i.e., the time spent 
upon the knees, should not be overlooked, especially in occupations with the most risk.

The application of hardening agents to the skin is of doubtful benefit. Control of the infective element in beat disorders appears to offer most hope of reducing the incidence.

Little is known of the factors which determine susceptibility to staphylococcal infection. Such infection is most frequent in the post-pubertal period, as seen in the younger miners of this series, suggesting a hormonal effect on resistance. Ointments containing hormones have been advocated for the prevention of skin infection (Whitelaw, 1951) but there is insufficient evidence to justify their use in miners. Most experience of staphylococcal infection is eventually followed by an increase in resistance to further infection but the mechanism by which immunity is gained is obscure. Whether immunization with staphylococcal vaccines or toxoid would help to protect men exposed to risk of beat disorder can only be determined by a controlled trial. Reduction in the carriage of pathogenic staphylococci, even solely in the injured areas, is likely to be difficult, since those staphylococci harboured in the follicles are inaccessible to any reasonable form of cleansing or antibacterial treatment. Indeed, the vigorous scrubbing often advised for preventing skin infection may cause harm by injuring infected follicles. Nevertheless, investigation into the effects of regular application of alcohol and other antiseptics would be desirable.

The present investigation has indicated that men differ widely in susceptibility to beat disorders, and that predisposition can be estimated with some success by simple methods.

It may not be possible, however, systematically to exclude susceptible individuals from work in low seams, since alternative work in standing height is not often available. Nevertheless, it should now be possible to recognize those persons for whom preventive measures are especially necessary.

Supervision of men at risk, and especially of those adjudged susceptible, in order to detect and treat infection while it is still confined to the neighbourhood of the follicle, offers perhaps the most practical approach to the problem. An important therapeutic measure in most cases is temporary transfer to work off the knees.

The carrier rates for pathogenic staphylococci found in this survey were slightly lower than those recorded by other workers. This is partly due to our stricter criteria of pathogenicity and to avoidance of enrichment methods of culture which, by revealing very scanty staphylococci, might have masked an association of heavier carriage with beat disorders. Higher rates of skin carriage might have been obtained if sites other than the knee had been tested but they would have been less relevant to this investigation.

\section{Summary}

Beat disorders and the factors causing them have been studied for a year in men working in conditions particularly hazardous in this respect.

Fifty-three attacks of beat knee and beat elbow arose from the extension of an obvious staphylococcal infection of a hair follicle into the adjacent subcutaneous tissue. There were seven attacks of apparently primary (acute) bursitis, one clearly the result of a severe injury. In some of the remaining six, the bursitis had been preceded by a local follicular infection.

In no attack of beat disorder observed in this series did a cut or abrasion appear to afford entry to the infecting organism.

Most beat conditions occurred in men who could be recognized as especially prone to staphylococcal infection. Of the 46 men who developed beat disorders while under observation, 39 had recently suffered from a staphylococcal infection, had previously had beat disorders, possessed a greasy skin, or were heavy carriers of pathogenic staphylococci. The remaining seven men suffered only mild attacks.

The complete exclusion of such susceptible men from work in narrow seams may seldom be practicable, but their recognition should assist the application of other preventive measures.

Phage-typing has shown that the strains of staphylococci responsible for infection are usually the same as those previously harboured at carrier sites.

We owe much to the cooperation of local officials of the National Coal Board and of the National Union of Mineworkers Lodge. Mr. T. Thomas, pit first-aid attendant, gave especially valuable help. Mr. G. Harries and Mr. C. H. H. Thomas ably assisted in the clerical and technical work.

We are indebted for helpful criticism of this paper to Dr. Scott Thomson and to Dr. R. E. O. Williams who also undertook the phage-typing.

Dr. E. Lewis Faning kindly helped in the presentation of the statistical data.

\section{REFERENCES}

Collis, E. L., and Llewellyn, T. L. (1924). Spec. Rep. Ser. med. Res. Coun. Lond., No. 89.

Marks, J. (1952). J. Path. Bact., 64, 175.

Watkins, J. T. (1951). Practitioner, 167, 257.

Whitelaw, M. J. (1951). J. clin. Endocr., 11, 487.

Williams, R. E. O., and Miles, A. A. (1949). Spec. Rep. Ser. med. Res. Coun. Lond., No. 266. 